\title{
Aspectos genéticos da actividade física. Estado actual do conhecimento baseado nos modelos animal e humano com amostras gemelares
}

*Maria Madalena Castro Oliveira ** José Antônio Ribeiro Maia

Resumo

A actividade física é um comportamento intima- $A$ mainpart of the total variance of this phenotype has to mente associado à qualidade de vida e àbe associated with another fundamental agent -the longevidade. A variação que este fenótipo apresen- phenotype.

ta no seio da população tem sido atribuída, essen-

cialmente, a determinantes de natureza socio- The work we are presenting wants to review, in an económica, demográfica e psicológica. Contudo, a quantidade de variância que explicam é reduzida $(<30 \%)$. A parte substancial da variação deste fenótipo tem de ser atribuída a um outro agente fundamental - o genótipo.

$\mathrm{O}$ trabalho que se apresenta pretende rever, de forma exaustiva, a investigação animal e humana, concretamente em delineamentos gemelares. $\mathrm{A}^{p h y}$ investigação pesquisada reflecte três expressões distintas do fenótipo actividade física: actividade física total, participação desportiva e dispêndio energético. Dos resultados emerge claramente a importância do patrimônio genético na variação interindividual da actividade física ao nível populacional e que na generalidade se cifra nos $\mathrm{O}$ progresso das sociedades modernas, particularmente nos $50-70 \%$.

Descritores: actividade física; animal; humana; genética.

\begin{abstract}
Physical activity is a behaviour associatedto quality oflife andlongevity. This phenotype presents variation at the population levei whose main determinants studiedare, essentially, socio-economic, demographic and psychological. Yet, expkined variance of these
\end{abstract} exhaustive way, animal and human research with the twin methodology. Main research has dealt with three different expressions ofthe phenotype physical activity - total physical activity, sports participation andenergy expenditure.

From the results emerges clearly the importance of genetic feature in the interindividual variation of physical activity at the population levei, whose main effect centres around $50-70 \%$.

Key words: physical activity; animal; human; genetics.

\section{Introdução}

níveis sócio-económico e tecnológico, ocasionou uma menor parcela dedicada ao esforço físico e operou significativas alterações no comportamento com repercussões significativas no quotidiano dos indivíduos.

Nestas sociedades, provavelmente pela primeira vez na história da humanidade, milhares de pessoas não necessitam de ser fisicamente activas para obterem alimento, para trabalharem ou para se deslocarem (Montoye e col., 1996; Sallis e Owen. 1999), sendo-lhes possibilitado, se assim o entenderem, a adopção de um estilo de vida sedentário.

E por muitos reconhecido (Bouchard e col., 1994; 


\begin{tabular}{r}
\hline \hline Um estilo de vida \\
sedentário é um \\
factor de risco para \\
um grande número \\
de doenças, que se \\
torna mais prevalente \\
com a idade, e que \\
acarreta um elevado \\
custo na redução da \\
qualidade de vida e \\
na longevidade. Em \\
contraste, a \\
actividade fisica \\
desordens emocionais \\
regular é considerada \\
um comportamento \\
com associações \\
diabetes, obeside cancro \\
benicas no estado de doenças \\
de saúde (Boucharde \\
Rankinen, 2001), \\
nomeadamente no \\
que respeita à
\end{tabular}

Sallis e Owen. 1999; Bouchard e Rankinen, 2001) que um estilo de vida sedentário é um factor de risco para um grande número de doenças, que se torna mais prevalente com a idade, e que acarreta um elevado custo na redução da qualidade de vida e na longevidade. Em contraste, a actividade física regular é considerada um comportamento com associações benéficas no estado de saúde (Bouchard e Rankinen, 2001), nomeadamente no que respeita à prevenção de doenças cardiovasculares, diabetes, obesida-

de, hipertensão, osteoporose, desordens emocionais e alguns tipos de cancro (Bouchard col., 1994; Killoron e col. 1994; MontoyeecoL, 1996; BlairecoL, 1999; Sallis e Owen, 1999; Kesaniemi e col., 2001). O forte corpo de evidências epidemiológicas, experimentais e clínicas acerca dos efeitos negativos do sedentarismo e das influências positivas de um estilo de vida fisicamente activo pode ser encontrado, por exemplo, na obra de Bouchard e col. (1994) e no relatório do Surgeon Generaldo Centro de Estudos de Doenças dos EUA (CDCQ1996).

De acordo com Bouchard e Rankinen (2001), o número de publicações acerca da actividade física e da inacti- vidade e dos seus efeitos num ou em vários factores de risco para determinadas doenças, bem como nos benefícios para a saúde ou nas taxas de mortalidade é cada vez mais elevado e adquire, actualmente, uma dimensão impressionante. Referem, no entanto, que a maioria dos estudos enfatizam os efeitos principais, valores médios dentro do grupo e diferenças entre grupos, prestando pouca atenção às diferenças interindividuais e à heterogeneidade do grupo e ao que determina a variação observável no seio da população.

E inequívoco que a actividade física, expressa de modo qualitativo ou quantitativo, apresenta uma grande variação no seio da população quanto ao tipo, duração, freqüência e intensidade (Maia, 2001). Ainda não são totalmente conhecidos em toda a sua extensão e interacção os determinantes dos níveis de actividade física habitual. Factores como a idade, sexo, estatuto socio-económico ou condições para a prática, a par de outros determinantes relacionados com o envolvimento social e físico, bem como aspectos psicológicos e fisiológicos, possuem papéis importantes no estilo de vida, mais ou menos activo, que cada um de nós adopta. De acordo com Casperson e col. (1998) estes factores, conjuntamente, só explicam 7. a 7, da variação observável nos níveis de actividade física habitual dos adolescentes, o que significa que está por explicar a maior parte da variação nos níveis de actividade física ao nível da população. Qual ou quais os factores subjacentes à parte da variação que Casperson e seus colaboradores consideram inexplicável? Há, com certeza, factores intrínsecos ao próprio indivíduo a determinar a variação interindividual neste comportamento. Factores como o genótipo e o envolvimento único provirão, com certeza, um papel determinante no nível de actividade física habitual de cada sujeito.

Em termos de Epidemiologia Genética, as características observáveis passíveis de quantificação num qualquer indivíduo são designadas de fenótipos isto é, a expressão métrica, em termos de traços discretos ou contínuos de um dado genótipo. A actividade física enquanto característica individual pode, e deve, ser entendida também como um fenótipo. 
Um fenótipo quantitativo contínuo - já que os níveis de actividade física se distribuem de acordo com a distribuição normal. Na sua essência, este fenótipo é de natureza complexa e multifactorial, resultado inequívoco da influência de múltiplos genes e distintos factores do envolvimento que atribuem a este comportamento uma marca indelével da história biológica e cultural da espécie humana (Bouchard e col, 1997; Maia, 2001; Plomin e col, 2000). Aquilo que caracteriza a natureza métrica dos fenótipos que suscita o interesse inquisitivo de um conjunto particular de investigadores é, tão simplesmente, a existência de diferenças interindividuais. Trata-se aqui de pesquisar não só a presença de variação e a sua quantificação, mas também a identificação das suas fontes e dos mecanismos que a regem. Até o observador menos atento é capaz de constatar que em fenótipos como o consumo de álcool e alcoolismo, o consumo de tabaco, o índice de massa corporal e a obesidade, ou as características das doenças cárdiovasculares, por exemplo, apresentam uma grande variação no seio da população (Turner e col., 1995). No domínio aplicado das Ciências do Desporto, fenótipos como o consumo máximo de oxigênio, a flexibilidade, os níveis de actividade física, os valores de aptidão física ou o grau de treinabilidade das aptidões e habilidades motoras, entre outros apresentam, também, uma enorme variação no seio de qualquer população num qualquer intervalo de idade (Bouchard e col., 1997; Plomin e col, 1997).

Como referimos anteriormente, a actividade física é hoje entendida como um fenótipo complexo de natureza multifactorial. A variação inequívoca dos valores deste fenótipo é governada por dois grandes agentes causais - os genes e o envolvimento (Bouchard e col, 1997; Maia, 2001; Plomin e col., 2000), ainda que a sua importância relativa possa variar em função da idade e do sexo.

A figura 1 pretende ilustrar a idéia de base desta pesquisa e que se centra no postulado de que este fenótipo é influenciado por um conjunto variado de factores (genes e envolvimento) que, numa dada população e num dado ponto da sua história, produz a variação observável.

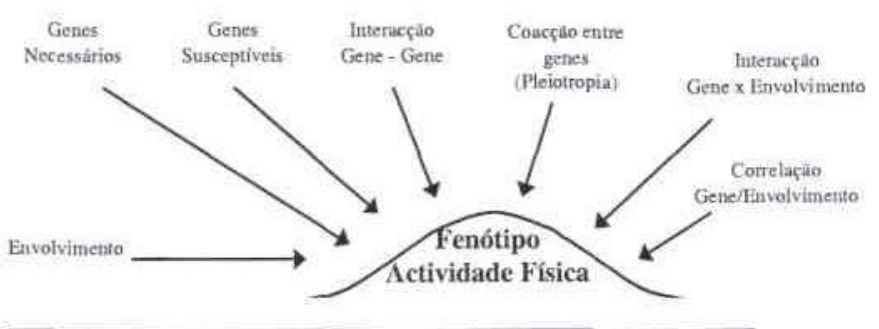

Figura 1: Factores condicionadores do fenótipo actividade física (adaptado de Bouchard e col., 1997).

Embora o fraccionamento da variação total em partes devidas às diferentes causas que governam a variação não seja uma tarefa difícil, o surgimento de novas tecnologias e processos de análise muito mais poderosos, no âmbito da

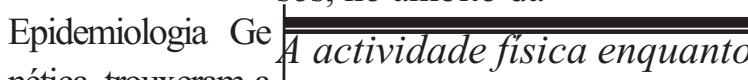
nética, trouxeram a promessa de uma visão mais detalha da e profunda do fenômeno (ver Flinte col., 1995; Bouchard e col., 1997). aracterística individual pode, e deve, ser entendida ambém como um fenótipo. Um fenótipo quantitativo contínuo -já que os níveis de actividade fisica se A distribuem de acordo com a Epidemiologia Ge distribuição normal. Na sua nética ocupa-se, na essência, este fenótipo é de sua essência, do es hatureza complexa e tudo da variabilida- multifactorial, resultado de humana tentan inequívoco da influência de do determinar as múltiplos genes e distintos relações entre a vafactores do envolvimento riação nas seqüên que atribuem a este cias de ADN, comportamento uma marca interacção entre indelével da história genes (fenômeno biológica e cultural da deepistasia),coac- espécie humana ção entre genes (fenômeno de pleiotropia),com estilos de vida dis tintos e outros fac tores 
1997) e pretende interpretar, numa primeira etapa, o quanto da variação presente nas diferenças entre sujeitos é atribuída a factores genéticos transmitidos no seio de famílias nucleares.

E inequívoco que dentro de uma qualquer população há variação genética. Com a excepção dos gêmeos monozigóticos, cada um de nós é geneticamente único. Conjuntamente à variação genética existe a variação do envolvimento. Os estudos realizados neste âmbito, com amostras constituídas por famílias nucleares ou gêmeos, interessam-se em pesquisar, numa primeira etapa, o quanto da variação observada no fenótipo é conseqüência da variação genética e quanto pode ser atribuído aos factores do envolvimento (Turner e col., 1995).

Encontram-se disponíveis na literatura duas abordagens para o estudo das bases genéticas de um dado fenótipo quantitativo: a metodologia do genótipo não medido ou não identificado, designada de Top-Down e a metodologia do genótipo medido ou identificado designada de Botton - Up, que se ilustra na figura 2 (Bouchardecol., 1997).

Figura 2: Abordagens disponíveis em Genética para o estudo de fenótipos de natureza contínua (adaptado de Bouchard

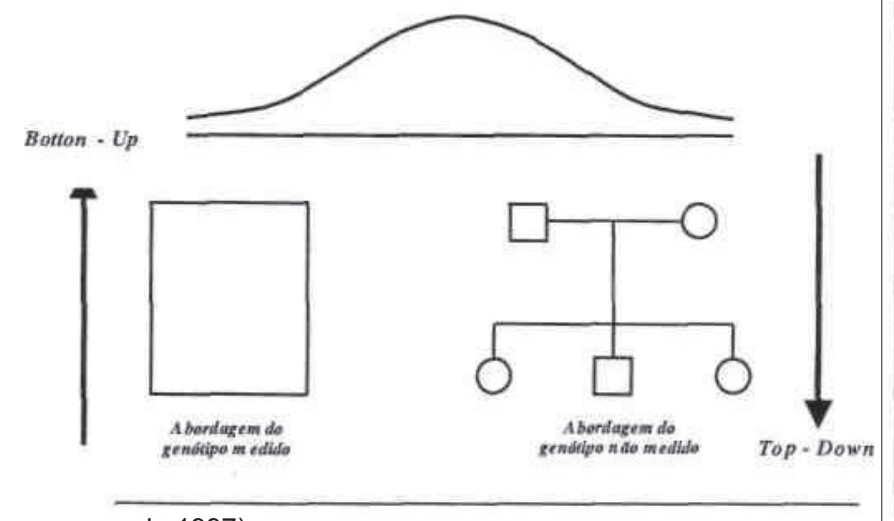

col., 1997).

A metodologia Top-Down baseia-se em análises estatísticas da variação observável no fenótipo em grupos de sujeitos geneticamente relacionados, isto é, famílias nucleares ou gêmeos. Essas análises estatísticas permitem estimar, na variação total presente no fenótipo, o quanto é devido à variação genética dos sujeitos. A metodologia Botton - $U p$ parte da variação na freqüência de um dado gene e tenta avaliar o impacto da variação ao nível do $\mathrm{ADN}$ no fenótipo quantitativo em estudo (Bouchard e col., 1997), recorrendo para tal a estudos de associação ou de linkage (uma análise exaustiva destas técnicas e procedimentos pode ser consultada emliu,1998).

O delineamento seqüencial implícito nos estudos de Epidemiologia Genética que se propõem estudar as bases genéticas de fenótipos quantitativos multifactoriais é composto pelas seguintes fases: (1) determinação de agregação familiar, isto é, a tendência para o fenótipo se aglomerar com freqüência no seio de famílias. A presença de agregação familiar pode ser testada calculando-se razões $\mathrm{F}$ em que se contrastam famílias nucleares entre si. Espera-se que haja diferenças substanciais entre famílias, relativamente à variação no seio de cada família (Bouchard e col., 1997; Maia e col., 2001); (2) quantificação da contribuição dos factores genéticos e do envolvimento responsáveis por essa agregação. Os métodos usados requerem abordagens em famílias nucleares ou gêmeos e análises estatísticas que permitam estimar, na variação total presente no fenótipo, o quanto é devido à variação genética dos sujeitos, ou seja, o cálculo da heritabilidade (Bouchard e col., 1997); (3) identificação de zonas específicas dos cromossomas onde se pensa estar um conjunto de genes (oligogenes) que contribuem de modo aditivo com percentagens de variância distinta para a expressão fenotípica total (isto é os quantitative trait loci- QTL's); (4) finalmente a localização dos genes e o esclarecimento dos seus mecanismos de acção. A combinação da Biologia Molecular com a Epidemiologia Genética, aliada aos grandes avanços a nível tecnológico, proporcionam o isolamento ou a localização de genes em determinadas zonas dos cromossomas responsáveis por certas doenças. As complexas análises de segregação aplicadas a fenótipos de natureza multifactorial, podem providenciar evidências estatísticas dos efeitos de um gene maior e podem ajudar no esclarecimento da forma como é herdado e transmitido. O desenvolvimento da abordagem que está inerente aos estudos dos quantitative trait loci, para traços ou fenótipos de 
natureza multifactorial, proporciona aos geneticistas a determinação dos suportes genéticos de um fenótipo sem o prévio conhecimento dos genes envolvidos (Bouchardecol.,1997).

\section{Objectivos}

A investigação sobre a temática dos factores genéticos que governam fenótipos quantitativos de natureza complexa é realizada com recurso aos modelos animal e humano. No modelo humano incluem-se pesquisas com delineamentos tão diversos como agregação em famílias nucleares, gêmeos, estudos de adopção, detecção de genes responsáveis por um determinado efeito e estudos de associação e linkage (Bouchard e col.1997).

A grande vantagem da pesquisa no modelo animal relativamente ao modelo humano é o controlo que se pode conseguir de diversos factores que normalmente confundem os resultados da investigação neste último. Um dos exemplos é o controlo da heterogeneidade genética pelo recurso a cruzamentos entre sujeitos com primeiro grau de parentesco (inbredstrains) ao longo de uma linhagem.

O propósito central deste trabalho é situar o estado actual do conhecimento no domínio dos aspectos genéticos da actividade física com base nos modelos animal e humano com amostras gemelares. No modelo animal incluem-se estudos de selecção e estudos de Quantitative Trait Loci. No modelo humano apresentam-se, exclusivamente, estudos realizados em gêmeos sobre a variação interindividual em diferentes fenótipos intimamente associados - actividade física, prática desportiva e dispêndio energético.

\section{Pesquisas em animais}

Os estudos que referiremos em seguida, realizados com ratos e moscas do vinagre, suportam a hipótese da variação dos valores da actividade física estar, parcialmente, na dependência do genótipo. A primeira pesquisa é um estudo de resposta à selecção. Os estudos de selec- ção pretendem evidenciar a presença da influência genética na variação de um dado traço/fenótipo/comportamento (por exemplo a actividade física), por forma a ser evidente uma resposta clara no diferencial de selecção. São realizados cruzamentos selectivos e sucessivos ao longo de uma linhagem, direccionados para a obtenção de valores médios superiores relativamente a um traço (por exemplo, no sentido em que os mais activos sejam cada vez mais activos), isto é, para uma distribuição distinta da dos progenitores, sobretudo nos seus valores médios.

DeFries e col. (1978) realizaram um estudo com o propósito de analisar a resposta à selecção de 30 gerações de ratos. Numa caixa de actividade sem qualquer obstáculo \{open field activity) um conjunto de feixes de células foto-eléctricas registava aspectos do comportamento dos animais. Os autores verificaram existir dois grupos extremos de ratos: enquanto uns temiam a caixa, defecavam, urinavam bastante (os níveis de defecação e urina estão relacionados com medo e baixa actividade) e se limitavam aos cantos da caixa, outros havia que a exploravam activamente não mostrando sinais de receio. Foram então constituídos para a pesquisa 3 grupos de ratos: o grupo de resposta elevada designados de muito activos; o grupo de resposta baixa ou de reduzida actividade; e um terceiro grupo, considerado de controlo, constituído por ratos escolhidos aleatoriamente. Os ratos mais activos foram cruzados entre si, o mesmo se passando com os ratos do grupo de menor actividade. Dos descendentes dos muito e pouco activos, os mais e os menos activos foram novamente seleccionados para acasalamento selectivo no seio de cada linhagem. Este processo de selecção foi repetido ao longo de 30 gerações. Nos ratos, uma geração demora apenas 3 meses. Desta pesquisa foi retirado o seguinte quadro de resultados e conclusões:

- conforme se observa na figura 3, ao longo das 30 gerações a selecção foi um sucesso. As linhagens mais activas tornaram-se cada vez mais activas e as linhagens menos activas cada vez menos activas. Importa esclarecer que a resposta à selecção só é bem sucedida se os factores hereditários forem importantes para o traço em estudo; 


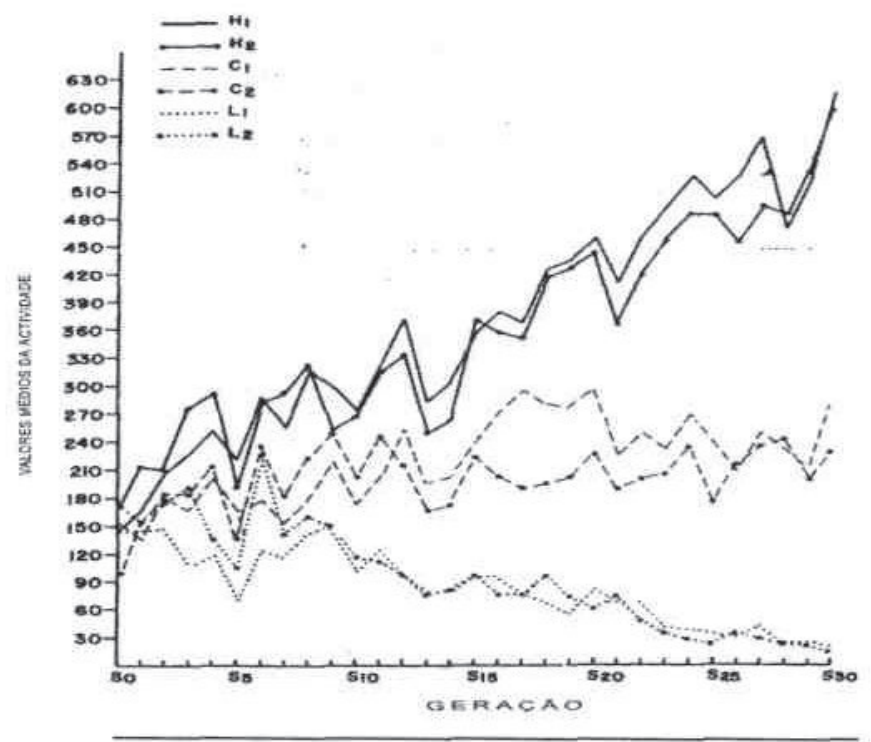

Figura 3: Valores médios da actividade física (open-field activity) de 6 linhagens de ratos, duas designadas muito activas $\left(\mathrm{H}_{1}\right.$ e $\left.\mathrm{H}_{2}\right)$, duas de reduzida actividade $\left(\mathrm{L}_{1}\right.$ e $\left.L_{2}\right)$ e duas de controlo $\left(\mathrm{C}_{1}\right.$ e $\mathrm{C}_{2}$ ) (adaptado de DeFries e col., 1997).

- ao fim de 30 gerações verificou-se uma diferença nos scores médios de actividade física 30 vezes superior nos mais activos relativamente aos menos activos. Os ratos da linhagem dos mais activos corriam o equivalente à distância de um campo de futebol durante os 6 minutos do teste, enquanto que os pertencentes às linhagens menos activas ficavam-se pelos cantos da caixa, a tremer;

- uma outra observação permitiu constatar que as diferenças entre a linhagem mais e menos activa aumentava em cada geração, sugerindo que um conjunto de genes contribuía para tal variação no comportamento. Se se tratasse somente de um ou dois genes responsáveis pelo comportamento, as duas linhagens separar-se-iam após algumas gerações e não divergiriam mais nas gerações futuras, o que não se verifica nesta pesquisa.

O estudo de Sokolowski e col. (1997), em moscas do vinagre (Drosophila melanogaster), veio mostrar que a variação natural de um gene determina um comportamento distinto: activas ou inactivas relativamente aos hábitos de busca de alimento. Os 20 anos de investigação dos autores em torno desta temática apontam para a existência de dois tipos de moscas: as extremamente enérgicas e activas na pro- cura de comida (rovers) e as sedentárias ou pouco activas (sitters). A Dra. Sokolowski e seus colaboradores conseguiram relacionar este comportamento distinto com uma variação natural num gene responsável pela produção de uma determinada enzima que afectava as células nervosas e cuja produção era menor nas moscas inactivas. Os autores mostraram que a variação no gene determinava se a mosca era activa ou inactiva e que uma pequena diferença na quantidade de enzima produzida alterava o comportamento. Para se certificarem que tinham encontrado o gene correcto, inseriram-no no núcleo de ovos de moscas inactivas e o resultado foi surpreendente: as moscas que resultaram desses ovos comportavam-se como activas, voando energicamente à procura de alimento.

O terceiro estudo que iremos focar refere-se a quantitative trait loci (QTL/s) e exige um esclarecimento prévio acerca do significado de QTL's.

Ronald Fisher sugeriu, pela primeira vez, que as características ou traços quantitativos eram governados por múltiplos genes, sendo portanto de natureza poligénica. Considerou que cada gene contribuía, de modo aditivo, com uma pequena percentagem para a variância total. Estava, pois, aberto o caminho para a conciliação das posições subjacentes às leis mendelianas relativas a fenótipos simples de natureza dicotômica com as idéias biométricas apresentadas por Francis Galton para traços quantitativos (Falconer, 1990). Durante a última década tem-se verificado uma convergência notória entre técnicas e procedimentos de genética quantitativa e de genética molecular, no sentido da identificação de zonas em determinados cromossomas ou de genes responsáveis por traços quantitativos de natureza complexa (Plomin e col., 1997). A investigação que se realiza em torno da temática da genética do comportamento à muito que tomou esta direcção no sentido de identificar genes específicos responsáveis por diferenças inter-individuais em vários comportamentos, mesmo aqueles que possuem características complexas e que são governados, simultaneamente, por factores génicos e do envolvimento, como é o caso da actividade física 
(Plomin e col.,1997).

Tal como referimos anteriormente, os traços quantitativos complexos, qualquer que seja a sua expressão num qualquer domínio da actividade humana, são influenciados por múltiplos genes e por múltiplos factores do envolvimento. Quantitative Trait Loci são um conjunto de genes (oligogenes) que contribuem de modo aditivo com percentagens de variância distinta para a expressão fenotípica total. A sua provável localização em zonas específicas de cromossomas é determinada por procedimentos rigorosos. Pensa-se que os QTL 's são responsáveis pela variação observável num traço sempre que se estudam elementos de famílias que se possam distinguir de modo mais ou menos dicotômico num dado fenótipo. Encontrar tais QTL's só foi possível nos últimos anos graças aos avanços registados a nível tecnológico. $\mathrm{O}$ modelo animal tem sido particularmente útil para este tipo de investigação (ver por exemplo Liu, 1998; Rogos ecoL, 1999).

Encontrar as zonas onde estarão alojados os genes responsáveis pelas diferenças inter- -individuais no comportamento actividade física tem sido o propósito de algumas pesquisas realizadas em ratos. Um dos delineamentos utilizados para identificar QTL's envolve a realização de acasalamentos sucessivos entre irmãos, pertencentes a uma mesma linhagem, e que se designa por recombinant inbred (RI) strains. Estes acasalamentos são extremamente úteis para este tipo de estudos porque permitem detectar a acção de múltiplos genes (QTL's) num determinado fenótipo. A variação intrastrain numa população de ratos RI serve como medida da influência dos factores do envolvimento e do erro experimental, enquanto que a variação interstrain reflecte, acima de tudo, diferenças genéticas (Mayedaecol., 1996).

Em humanos, cruzamentos experimentais desta natureza não são possíveis de realizar, o que não impede os investigadores de utilizarem outros delineamentos (sobre esta matéria ver, por exemplo, Rogers e col., 1999; Plomin e col., 2000). No entanto, devido ao elevado grau de homogeneidade do genoma entre mamíferos, os QTL's identificados no modelo animal permitem, $\grave{a}$ posteriori, a identificação, no cromossoma humano, de regiões homólogas que subseqüentemente poderão ser testados através dos métodos de associação ou linkage (Bouchard e col.,1997).

Mayeda \& Hofstetter (1999) orientaram a sua pesquisa para a identificação de QTL's influenciadores do ritmo circadiano da actividade de ratos. $\mathrm{O}$ sistema circadiano produz a nível fisiológico e comportamental ritmos que têm uma duração cíclica que se designa por período. Este período, nos ratos, é governado por vários genes. Pesquisas anteriores mostraram que no cromossoma 1 destes animais existia uma região entre $90 \mathrm{e}$ $100 \mathrm{cM}^{1}$, isto é, um QTL, responsável pela governação deste ciclo para a actividade locomotora (Mayedae col. 1996).

Os autores investigaram uma linhagem de ratos RI strain que possuía uma alteração congênita na região onde estaria esse QTL. Os resultados mostraram que estes ratos possuíam um período circadiano mais reduzido, confirmando que naquela região existe um QTL responsável pelas diferenças neste traço. Ronald Fisher sugeriu, pela primeira vez, que as características ou traços quantitativos eram governados por múltiplos genes, sendo portanto de natureza poligénica. Considerou que cada gene contribuía, de modo aditivo, com umapequena percentagem para a variância total. Estava, pois, aberto o caminho para a conciliação das posições subjacentes às leis mendelianas relativas afenótipos simples de natureza dicotômica com as idéias biométricas apresentadas por Francis Galtonpara traços quantitativos Adicionalmente, os dados desta pesquisa sugeriram também que nesta mesma região do cromossoma 1 existe um quantitative trait loci responsável não só pela quantidade média de actividade diária dos ratos mas também pelo seu padrão de actividade locomotora. Um outro estudo realizado também em ratos RI strain 
com o propósito de detectar regiões nos cromossomas que estivessem associadas com a actividade física, permitiu identificar um QTL, no cromossoma 15, relacionado com a actividade física destes animais (Flint $\mathrm{e}$ col.,1995).

\section{Pesquisas em humanos}

Os delineamentos utilizados em epidemiologia genética para estudar a variação que ocorre no seio da população para qualquer traço métrico humano não são tão poderosos ou directos como os que resultam de estudos de selecção ou de inbred strains, que atrás referimos. A pesquisa em humanos não recorre a populações geneticamente definidas, tais como inbred strains ou manipulações experimentais muito controladas do envolvimento. Pelo contrário, limita-se ao estudo de ocorrências genéticas naturais e variações do envolvimento. No entanto, este empreendimento é, só por si, suficientemente complexo e elucidativo para informar acerca da importância de factores génicos na regulação da variação.

A natureza proporcionou aos investigadores situações experimentais únicas para o teste de hipóteses acerca da influência relativa dos genes e do envolvimento num determinado traço, característica ou comportamento humanos - o nascimento, crescimento e desenvolvimento de gêmeos idênticos e fraternos.

Os gêmeos idênticos ou monozigóticos (MZ) - cerca de $1 / 3$ das gestações gemelares - resultam da divisão precoce de um zigoto proveniente da fecundação de um único óvulo por um só espermatozóide, produzindo assim dois indivíduos (ou mais) do mesmo sexo e geneticamente idênticos. Em 30\% dos casos, a divisão do zigoto ocorre nas primeiras 72 horas após a fertilização, pelo que a gestação será bicoriónica e biamniótica, isto é, existem duas placentas (mesmo que fundidas) e tecido corial interposto entre as duas cavidades amnióticas. Se a divisão se der entre 4 e 8 dias após a fertilização a placenta será única, mas cada feto terá a sua própria cavidade amniótica (gestação monocoriónica- biamniótica), o que se verifica em cerca de $65 \%$ dos casos. Se o zigoto se divide entre o $9^{\circ}$ e o $13^{\circ}$ dias após a fertilização, $5 \%$ dos casos, haverá uma só placenta e uma só cavidade amniótica para ambos os fetos (gravidez monocoriónica- monoamniótica). Por último, ocorrerão gêmeos siameses se a divisão do zigoto acontecer depois do $13^{\circ}$ dia após a fertilização (Graça, 1996).

Os gêmeos fraternos ou dizigóticos (DZ) - cerca de 2/3 das gestações múltiplas - resultam da fecundação de dois óvulos por diferentes espermatozóides, pelo que podem ser de sexos diferentes e o seu patrimônio genético variar de acordo com a contribuição materna e paterna contida nas diferentes células fecundadas e fecundantes. Em termos médios, e dentro da população, considera-se que são geneticamente semelhantes em $50 \%$ dos seus genes, situação idêntica à que se passa com qualquer tipo de parentes em $\mathrm{I}^{\mathrm{O}}$ grau. A gestação é sempre bicoriónica e biamniótica (Graça, 1996).

Em estudos gemelares parte-se do princípio que os gêmeos MZ repartem 100\% dos seus genes (sendo portanto cópias genéticas, isto é, possuem o mesmo genótipo) enquanto que os $\mathrm{DZ}$, tal como acontece com todos os irmãos, repartem em termos médios 50\% do seu patrimônio genético (Falconer, 1990; Khounyecol., 1993). Como se tornará evidente, se os factores genéticos forem importantes para um determinado traço ou comportamento, os indivíduos que compõem o par de gêmeos $\mathrm{MZ}$, geneticamente idênticos, serão mais semelhantes entre si do que os do par DZ, semelhantes apenas em $50 \%$ dos seus genes. Uma forte divergência intrapar nos gémeos MZ traduzirá, como é obvio, uma forte influência do envolvimento para um qualquer fenótipo.

Uma busca exaustiva $^{2}$ acerca da investigação empírica no domínio da influência dos genes e do envolvimento na actividade física em gémeos produziu resultados escassos. Foram localizados quatro textos sobre a actividade física e mais quatro sobre a participação desportiva. Aparticipação desportiva assume aqui uma expressão distinta da actividade física, isto é, representa apenas uma fracção da actividade física total do 


\begin{tabular}{|c|c|c|}
\hline Fenótipo/autor & Pais & Amostra \\
\hline $\begin{array}{l}\text { Actividade física } \\
\text { Kaprio ecol. (1981)-AF no tempo de lazer } \\
\text { "Habitos tabágicos, consumo de dlcoole e actividade fisica } \\
\text { no tempo de lazer, em gémeos do sexo masculino" }\end{array}$ & Finlândia & $\begin{array}{l}\text { 4594 pares de gémeos }(1537 \mathrm{MZ}+3057 \\
\text { DZ) masculinos, com mais de } 18 \text { anos }\end{array}$ \\
\hline $\begin{array}{l}\text { Lauderdale ecol. (1997)-AF moderada eintensa } \\
\text { "Determinantes familiares para a actividade fisica intensa } \\
\text { e moderada: um estudo em gémeos" }\end{array}$ & BA & $\begin{array}{l}3344 \text { pares de gémeos, todos dos sexo } \\
\text { masculino, dos } 33 \text { aos } 51 \text { anos }\end{array}$ \\
\hline $\begin{array}{l}\text { Aarnioe col. (1997)-AF no tempo de lazer } \\
\text { "Agregą̧äo familiar na actividade fisica no tempo de } \\
\text { lazer - um estudo em três geraçōes" }\end{array}$ & Finlândia & $\begin{array}{c}3254 \text { pares de gémeos (1697 MZe DZ } \\
\text { femininose } 1557 \mathrm{MZ} \text { e DZ masculinos), } \\
\text { com } 16 \text { anos, e seus paise avós }\end{array}$ \\
\hline $\begin{array}{l}\text { Pérusse ecol. (1989) - AF habitual e participaçáo em exercício } \\
\text { "Influências genéticas e do envolvimento nos niveis } \\
\text { de actividade fisica habitual e participaçāo em exercicio fisico" }\end{array}$ & Canadá & $\begin{array}{l}1610 \text { membros de } 375 \text { familias, ondese } \\
\text { indufam } 62 \text { pares de gémeos } \mathrm{MZ} \text { e } 60 \mathrm{DZ}\end{array}$ \\
\hline $\begin{array}{l}\text { Maia (2001) - Actividade fisica total } \\
\text { "Aspectos genéticos da actividade fisica. } \\
\text { Um estudo univariado em gémeos" }\end{array}$ & Portugal & $\begin{array}{l}411 \text { pares }(203 \mathrm{MZ}+208 \mathrm{DZ}) \text { de ambos } \\
\text { os sexos, dos } 12 \text { aos } 25 \text { anos }\end{array}$ \\
\hline $\begin{array}{l}\text { Participação desportiva } \\
\text { Boomsmaecol. (1989) } \\
\text { "Semelhança parental e de gémeos na participą̧äo } \\
\text { desportiva e frequência cardiaca" }\end{array}$ & Holanda & $\begin{array}{c}90 \text { pares de gémeos }(44 \mathrm{MZ}+46 \mathrm{DZ}) \\
\text { dos } 14 \text { aos } 20 \text { anos e seus pais }\end{array}$ \\
\hline $\begin{array}{l}\text { Koopman ecol.(1994) } \\
\text { Tabagismo eparticipą̧äo desportiva" }\end{array}$ & Holanda & $\begin{array}{l}1578 \text { pares de gémeos }(578 \mathrm{MZ}+1000 \\
\mathrm{DZ}) \text {, dos } 13 \text { aos } 22 \text { anos e seus pais }\end{array}$ \\
\hline $\begin{array}{l}\text { Beunen \& Thomis (1999) } \\
\text { "Determinantes genéticos da participaçẫo desportiva } \\
\text { eactividade fisica diária" }\end{array}$ & Bégica & $\begin{array}{c}91 \text { pares }(36 \mathrm{MZ}+55 \mathrm{DZ}) \text { com } 15 \text { anos } \\
\text { de idade }\end{array}$ \\
\hline $\begin{array}{l}\text { Maiaecol. (1999) } \\
\text { "Aspectos genéticos da prática desportiva: um estudo em gémeos" }\end{array}$ & Portugal & $\begin{array}{l}104 \text { pares de gémeos }(40 \mathrm{MZ} \text {, idade }= \\
17,30 \pm 5.82 ; 64 \mathrm{DZ} \text {, idade }=17.86 \pm 8.12)\end{array}$ \\
\hline $\begin{array}{l}\text { Dispêndio energético } \\
\text { Fontaine ecol. (1985) } \\
\text { Taxa metabólica basalem gémeos } M Z e D Z "\end{array}$ & Canadá & $\begin{array}{l}39 \text { pares }(20 \mathrm{MZ} \text {, idade }=20.6 \pm 2.9 \\
\text { e } 19 \mathrm{DZ} \text {, idade }=21.4 \pm 3.1)\end{array}$ \\
\hline $\begin{array}{l}\text { Bouchard e col. (1989) } \\
\text { "Efeito genético nas taxas metabolicas de repouso e de exercicio" }\end{array}$ & Canadá & $\begin{array}{l}58 \text { pares }(21 \mathrm{DZ}+37 \mathrm{MZ}) \text { com mais } \\
\text { de } 14 \text { anos }\end{array}$ \\
\hline $\begin{array}{l}\text { Goran (1997) } \\
\text { "Influências genéticas no dispêndio energético humano } \\
\text { e na utilizaçấo de substratos" }\end{array}$ & USA & $\begin{array}{l}\text { 37 pares de irmä́os, } 5 \text { dos quais eram } \\
\text { gémeos } \mathrm{DZ} \text {, dos } 5 \text { aos } 9 \text { anos }\end{array}$ \\
\hline
\end{tabular}

Tabela 1: Inventário de estudos gemelares sobre a temática da influência dos genes e do envolvimento na actividade física, na participação desportiva e no dispêndio energético. 
sujeito. Como a presente pesquisa também trata de dados relativos ao dispêndio energético, são referidos, também, alguns estudos realizados com gêmeos. Na tabela 1 encontram-se, em síntese, os resultados dessa busca.

\subsection{Estudos de Actividade Física}

Kaprio e col. (1981) pesquisaram a influência dos genes e do envolvimento na actividade física de gêmeos. Os autores investigaram o fenótipo actividade física no tempo de lazer numa amostra constituída por 1537 pares de gémeos MZ e 3057 DZ com mais de 18 anos, todos do sexo masculino (detalhes na tabela 2).

\begin{tabular}{cccc}
\hline \multirow{2}{*}{$\begin{array}{c}\text { Grupos de idade } \\
\text { (anos) }\end{array}$} & \multicolumn{3}{c}{ n.o de pares por zigotia } \\
\cline { 3 - 4 } & $M E$ & LE \\
\hline 1829 & $\cdots$ & 731 & 1628 \\
$30-39$ & $\cdots$ & 351 & 812 \\
4049 & & 191 & 560 \\
5059 & & 137 & 300 \\
$60+$ & & 127 & 204 \\
\hline Total & 1537 & 3507
\end{tabular}

Tabela 2: Distribuição dos pares de gêmeos de diferente zigotia por grupos de idade (adaptado de Kaprio e col. 1991).

Através de um questionário elaborado para o efeito, foram obtidas informações acerca da intensidade e duração das actividades físicas, dos anos de participação nas referidas actividades, da actividade física no trabalho e da percepção subjectiva do sujeito acerca do seu nível de actividade física diária. Estas variáveis foram submetidas a uma análise factorial para se obter scores factoriais de actividade física que posteriormente foram objecto de tratamento estatístico da análise de variância, por forma a ser possível calcular coeficientes de correlação intraclasse dos gêmeos MZ e DZ e as estimativas de heritabilidade por grupos de idade.

\begin{tabular}{cccc}
\hline & \multicolumn{2}{c}{ Correlação intraclasse } & \\
\cline { 2 - 3 } Grupos de idade & toz & bz & $\mathrm{h}^{2}$ \\
\hline $18-29$ & 0.64 & 0.32 & 0.64 \\
$30-39$ & 0.48 & 0.22 & 0.52 \\
40.49 & 0.32 & 0.11 & 0.43 \\
50.59 & 0.30 & 0.14 & 0.32 \\
$60+$ & 0.33 & 0.01 & 0.62 \\
\hline Total & 0.57 & 0.26 & 0.62 \\
\hline
\end{tabular}

Tabela 3: Valores dos coeficientes de correlação intraclasse (t) e estimativas de heritabilidade $\left(h^{2}\right)$ por intervalos de idade (adaptado de Kaprio e col. 1991).

O valor de heritabilidade para o total da amostra é de $62 \%$ evidenciando a presença substancial de efeitos genéticos nos níveis de actividade física.

Lauderdale e col. (1997) investigaram o contributo dos factores genéticos e do envolvimento nos diferentes níveis de actividade física voluntária de 3344 pares de gêmeos, com idades compreendidas entre os 33 e os 51 anos, todos do sexo masculino. Para o estudo da heritabilidade foram utilizados, apenas, 1006 pares MZ e 530 DZ. A actividade fisica foi avaliada a partir de um questionário com dois grupos de questões. $\mathrm{O} 1^{\circ}$ grupo, com 6 itens, pretendia avaliar a actividade física moderada associada a actividades como, por exemplo, a marcha e subir escadas, enquanto que o $2^{\circ}$ grupo, com 5 itens, avaliava a participação regular em actividades intensas específicas tais como a prática corrida, ciclismo, natação e jogos de raquete.

Os investigadores delinearam uma estratégia analítica capaz de dar resposta a duas das principais questões da epidemiologia genética: (1) Será que o fenótipo actividade física tende a agregar-se em famílias? (2) Estará a agregação familiar relacionada com a exposição a um dado envolvimento, susceptibilidade biológica herdada, ou a herança cultural? Os principais resultados e conclusões foram os seguintes:

- há um padrão semelhante de freqüência das respostas dos gêmeos MZ e DZ para as actividade físicas moderadas e intensas; 
- para cada actividade moderada e intensa, as correlações dos MZ são sempre superiores à dos DZ o que sugere um efeito genético na variação do fenótipo observado;

- as correlações para os MZ vão de 0.27 a 0.58 enquan:: :_e para os DZ vão de 0.07 a 0.44 ;

- : ira ai a atividades consideradas intensas, como por exemplo a marcha ou corrida, jogos de raquete, ou ciclismo, os valores de heritabilidade são de 0.53 , 0.48 e 0.58 respectivamente;

- para as seis actividades consideradas moderadas os valores de heritabilidade vão de 0.12 a 0.40 ; o índice de heritabilidade para as actividades moderadas é de

- nesta pesquisa, não se verificou a presença da influir.aa aos ractores do envolvimento comum.

Aarnio e col. (1997) estudaram 3254 pares de gêmeos com lóanos (1697 MZ e DZ femininos e 1557 MZ e DZ masculinos), seus pais e avós, com o propósito de investigar as associações intra e intergeracional na activi-dade física no tempo de lazer no seio da família, no con-junto das três gerações. A actividade física foi avaliada através de um questionário distinto para cada geração cue permitiu estimar os valores representativos de ac-tividade física nos tempos de lazer. Os resultados relevantes para o nosso estudo são os seguintes:

\begin{tabular}{ccc}
\hline & Correlaçáo (r) & n.* de pares \\
\hline $\mathrm{MZ}_{\mathrm{f}}$ & 0.64 & 231 \\
$\mathrm{M}_{\mathrm{w}}$ & 0.72 & 147 \\
$\mathrm{DZ}_{\mathrm{f}}$ & 0.41 & 179 \\
$\mathrm{DZ}_{\mathrm{w}}$ & 0.45 & 191 \\
$\mathrm{DZ}_{\mathrm{v}}$ & 0.22 & 437 \\
\hline
\end{tabular}

$\mathrm{f}$-feminino: $\mathrm{m}$-masculino; so-sexo oposto

Tabela 4: Valores de correlação na prática de actividade física no tempo de lazer dos gêmeos MZ e DZ.

As correlações mais elevadas são entre os pares MZ masculinos e MZ femininos, enquanto que os gêmeos DZ de sexo oposto apresentam a correlação mais baixa.
Face ao padrão de correlação $-r_{\mathrm{MZXF}}>\mathrm{r}_{\mathrm{DZf}}$ e $\mathrm{r}_{\mathrm{MZm}}>$ $\mathrm{r}_{\mathrm{DZm}}$-é evidente a presença de efeitos genéticos e do envolvimento único dos membros de cada par.

O estudo de Pérusse e col. (1989) foi realizado numa amostra de 1610 membros de 375 famílias. Nesta amostra estavam incluídas famílias com gêmeos $\mathrm{MZ}$ (62 pares) e DZ (60 pares). Os autores tiveram como propósito identificar os efeitos das influências genéticas e do envolvimento no que consideraram ser dois indicadores de actividade física - actividade física habitual e participação em exercício físico. Um questionário detalhado, e que pode ser aplicado tanto nas crianças como nos adultos, permitiu quantificar e estimar os níveis desses dois indicadores. De seguida, apresentam-se, exclusivamente, os resultados relativos aos valores de correlação intraclasse dos gêmeos, por serem aqueles que demostram pertinência para a presente pesquisa. Estes resultados não são apresentados por sexo, pelo facto de não estarem disponíveis no texto original.

\begin{tabular}{ccc}
\hline & $\begin{array}{c}\text { Níveis de actividade } \\
\text { física habitual }\end{array}$ & $\begin{array}{c}\text { Participaçáo } \\
\text { em exercício }\end{array}$ \\
\hline $\mathrm{DZ}(\mathrm{n}=56)$ & 0.62 & 0.76 \\
$\mathrm{MZ}(\mathrm{n}=55)$ & 0.72 & 0.74 \\
\hline
\end{tabular}

Tabela 5: Valores de correlação intraclasse dos gêmeos DZ e MZ para a actividade física habitual e participação em exercício.

No que se refere aos níveis de actividade física habitual o valor de correlação dos $\mathrm{MZ}$ não é muito superior ao dos DZ. Para a amostra total do estudo não foi encontrado um efeito genético muito elevado dado que a estimativa de heritabilidade foi de $29 \%$. A maior relevância nas diferenças nos níveis de actividade física foi atribuída aos factores do envolvimento não transmitidos pelos progenitores, $71 \%$.

Para a participação em exercício é de notar que o valor de correlação intraclasse dos pares de gêmeos DZ é ligeiramente superior ao dos MZ. No total da amostra, a totalidade da variância foi atribuída ao envolvimento culturalmente partilhado no seio da família (12\%) e ao envolvimento único dos sujeitos (88\%). Não foram observados efeitos genéticos já que $\mathrm{h}^{2}=0$. 
Do nosso conhecimento só existe uma pesquisa em Portugal sobre esta temática. Foi realizada por Maia (2001) com o propósito de estimar a quantidade de efeitos genéticos responsáveis pela variação inequívoca nos | níveis de actividade física de gêmeos $\mathrm{MZ}$ e DZ. A amostra foi constituída por 411 pares de gêmeos de diferente zigotia dos 2 sexos, com idades compreendidas entre os 12 e os 25 anos. O fenótipo actividade física total foi obtido a partir do questionário de Baecke e col. (1982).

Na tabela 6 são apresentados os resultados relativos às correlações de Pearson para o índice de actividade física total nos gêmeos de diferente zigotia e sexo.

\begin{tabular}{lccccc}
\hline & $\mathrm{MZ}_{\mathrm{m}}$ & $\mathrm{DZ}_{\mathrm{n}}$ & $\overline{\mathrm{Mq}}$ & $\overline{\mathrm{DZ}_{4}}$ & $\mathrm{DZ}_{\mathrm{s}}$ \\
\hline Pares $(\mathrm{n})$ & 8 & $\mathrm{Q}$ & 118 & 85 & 55 \\
rde Pearson & 0.71 & 0.43 & 0.80 & 0.70 & 0.44 \\
\hline
\end{tabular}

( $s o=$ sexo oposto; $\mathrm{m}=$ masculino; $\mathrm{f}=$ feminino $)$

Tabela 6: Correlações de Pearson para o índice de actividade física total nos gêmeos de diferente zigotia e sexo.

Face a estes resultados, o autor refere o seguinte: o 1 padrão de correlações nos gêmeos do sexo masculino sugere, de modo inequívoco, a presença de efeitos genéticos e do envolvimento comum e único a governar I a variação nos níveis de actividade física. $\mathrm{O}$ mesmo não parece ser o caso no sexo feminino, dado que o valor de correlação dos gêmeos DZ é muito próximo do dos gêmeos MZ.

O autor usou 16 modelos alternativos para o teste de diferentes possibilidades de combinação de factores génicos e do envolvimento por forma a explicar a variância e covariância presente nos dados dos gêmeos MZeDZ. Essa metodologia de ajustamento de modelos, utilizada em Biometria Genética (ver Neale e Cardon, 1992), revelou que o que melhor se ajustou é o que sugere que efeitos genéticos (A), do envolvimento comum $(\mathrm{C})$ e do envolvimento único e aleatório $(\mathrm{E})$ governam de modo distinto a variância observada no fenótipo em causa nos dois sexos (modelo escalar específico do sexo ACE). Os efeitos calculados para cada sexo são, em termos de percentagem de variância total, os seguintes:

Tabela ${ }^{*}$ ARABIC 7: Estimativas de variância dos parâmetros fundamentais do modelo genético (ACE) em cada sexo.

\begin{tabular}{lccc}
\hline Sexo & $\mathrm{a}^{2}$ & $\mathrm{c}^{2}$ & $\mathrm{e}^{2}$ \\
\hline Masculino & $68 \% \%$ & $20 \%$ & $11.6 \%$ \\
Feminino & $398 \%$ & $28 \% \%$ & $31.8 \%$ \\
\hline
\end{tabular}

\subsection{Estudos de Prática Desportiva}

A pesquisa de Boomsma e col. (1989) foi realizada em 90 pares de gêmeos (idade: dos 14 aos 20 anos) e respectivos pais, com o propósito de estudar a semelhança dos gêmeos e dos progenitores no que à participação desportiva dizia respeito. A informação sobre a prática desportiva foi recolhida através de uma questão que implicava uma resposta de natureza dicotômica, sim ou não. A questão era a seguinte: está envolvido em actividades desportivas?

Da análise dos dados foram obtidos os resultados apresentados na tabela 8 .

\begin{tabular}{lccccc}
\hline & $\mathrm{MZ}_{\mathrm{m}}$ & $\mathrm{MZ}_{\mathrm{f}}$ & $\mathrm{DZ}_{\mathrm{m}}$ & $\mathrm{D} Z_{\mathrm{f}}$ & $\mathrm{DZ}_{\mathrm{w}}$ \\
\hline Pares (n) & 16 & 28 & 15 & $\overline{7}$ & 14 \\
$\mathrm{r}_{\mathrm{f}}$ & 0.89 & 090 & 0.14 & 0.70 & -0.02 \\
\hline
\end{tabular}

Tabela 8: Valores de correlação tetracóricos $\left(r_{t}\right)$ no seio de cada par de diferente zigotia.

Os valores de correlação encontrados para o par do sexo feminino sugerem a presença do envolvimento comum dos membros de cada par. Para o sexo masculino, em contraste, essa presença não é tão evidente, uma vez que a correlação dos DZ é muito menor que o valor esperado relativamente aos MZ. Baseado nestes valores, a contribuição dos factores genéticos e dos não genéticos (envolvimento) parecem diferentes nos sexos feminino e masculino. $\mathrm{O}$ valor de correlação de zero, encontrado nos gêmeos $\mathrm{DZ}$ de sexo oposto, sugere a presença de factores diferentes a contribuir para a variância na participação desportiva em rapazes e raparigas. 
Utilizada a metodologia de ajustamento de modelos para interpretar a contribuição distinta dos factores genéticos e do envolvimento na variância e covariância observadas nos gêmeos MZ, DZ e DZ de sexo oposto, foram obtidos os resultados apresentados na tabela 9 .

\begin{tabular}{lcc}
\hline & $\mathrm{a}^{2}$ & $\mathrm{e}^{2}$ \\
\hline Sowfeminino & 0.35 & 0.65 \\
Sowmascalino & 0.77 & 0.23 \\
\hline
\end{tabular}

Tabela 9: Estimativas de variância para os factores genéti$\cos \left(\mathrm{a}^{2}\right)$ e do envolvimento único $\left(\mathrm{e}^{2}\right)$.

No sexo feminino os factores do envolvimento representam a maior contribuição para a variância observada respostas à prática desportiva. $\mathrm{O}$ contrário se passa para o sexo masculino já que a maior influência para a prática desportiva parece residir nos factores genéticos, sendo $\mathrm{a}^{2}$ (fracção da variância fenotípica imputada às diferenças genéticas entre sujeitos) 0 dobro do obser-vado no sexo feminino.

O segundo estudo holandês, da autoria de Koopmans e coL (1994) foi realizado numa amostra de maior dimensão, constituída por 1578 gêmeos com idades compreendidas entre os 13 e os 22 anos e respectivos pais. Teve como propósito identificar os factores genéticos e do envolvimento responsáveis pelos hábitos tabágicos e de prática desportiva, ainda que aqui só o último fenótipo seja do nosso interesse.

A resposta dicotômica à questão - pratica desporto? produziu os valores de correlação tetracóricos, apresentados na tabela 10 .

\begin{tabular}{|c|c|c|c|c|c|}
\hline & $\mathrm{MZ}_{m}$ & $\mathrm{DZ}_{\mathrm{m}}$ & $M_{\mathrm{r}}$ & $\ddot{U} L_{\mathrm{t}}$ & $D Z$ \\
\hline Pares (n) & 249 & 241 & 329 & 303 & 456 \\
\hline & 0.89 & 0.60 & 0.85 & 0.72 & 035 \\
\hline
\end{tabular}

Tabela 10: Valores de correlação tetracóricos $\left(r_{t}\right)$ dos diferentes pares de gêmeos.

Estes valores mostram que os pares de gêmeos $\mathrm{MZ}$ são mais semelhantes do que os $\mathrm{DZ}$ na prática desportiva, sugerindo que factores genéticos contribuem para as diferenças inter-individuais neste comportamento.
Não se constataram diferenças significativas nos valores de $r_{\text {MZm }}$ e $r_{\text {MZF }}$ bem como nos $r_{\text {DZm }}$ e $r_{\text {DZF. }}$ O valor

de correlação para os DZ de sexo oposto é significativamente mais baixo que os valores dos $\mathrm{DZ}$ do mesmo sexo. Isto sugere factores diferentes a influenciar o comportamento do sexo masculino e feminino, isto é, genes e envolvimento comum expressos num sexo, provavelmente não se expressarão na mesma magnitude no sexo oposto.

Quando se testaram as hipóteses subjacentes ao padrão dos resultados anteriores, verificou-se que a contribuição dos factores genéticos e do envolvimento não difere entre sexos. As estimativas foram as seguintes: $\mathrm{a}^{2}=$ $48 \%$; $\mathrm{c}^{2}$ (fracção da variância fenótipica imputada aos efeitos do envolvimento comum) $=38 \%$; $\mathrm{e}^{2}$ (fracção da variância fenotípica imputada aos efeitos do envolvimento único dos sujeitos) $=12 \%$.

O estudo proveniente da Bélgica foi realizado por Beunen \&Thomis (1999) numa amostra de 91 pares de gêmeos $\mathrm{MZ}$ e DZ, com 15 anos de idade. A variável estudada foi o número de horas/semana/ano despendidas na prática desportiva realizada no clube, com os amigos e/ou com a família, exceptuando o número de ho-

\begin{tabular}{lccccc}
\hline & $\mathrm{MZ}_{\mathrm{m}}$ & $\mathrm{MZ}_{1}$ & $\mathrm{DZ}_{\mathrm{m}}$ & $\mathrm{DZ}_{1}$ & $\mathrm{DZ}_{\mathrm{w}}$ \\
\hline Pares (n) & $\overline{7}$ & $\bar{\nabla}$ & 19 & 19 & 19 \\
rdePearson & 0.66 & 0.98 & 0.62 & 0.71 & 0.23 \\
\hline
\end{tabular}

ras das aulas de Educação Física. Os valores de correlação obtidos neste fenótipo estão na tabela 11.

Tabela 11: Valores do coeficiente de correlação de Pearson nos diferentes pares de gêmeos.

As correlações intrapar no sexo feminino são superiores às do sexo masculino. $\mathrm{O}$ valor de $\mathrm{r}_{\mathrm{DZf}}$ é mais de metade do valor $\mathrm{r}_{\mathrm{MZf}}$, sugerindo que os factores do envolvimento jogam um papel importante na prática desportiva.

O valor de correlação dos $\mathrm{DZ}$ (0.23) foi muito menor do que os valores encontrados para os DZ do mesmo sexo. Estas diferenças poderão ficar a dever-se a diferente susceptibilidade biológica na prática desportiva.

O recurso ao procedimento de ajustamento de 
modelos produziu os seguintes resultados:

- no sexo masculino o modelo ACE produziu $\mathrm{a}^{2}=83 \%$, $\mathrm{c}^{2}=0 \%, \mathrm{e}^{2}=17 \%$, o que permite concluir que nesta amostra, o tempo despendido na prática desportiva é fortemente dependente dos genes;

- no sexo feminino, o mesmo modelo revelou $\mathrm{a}^{2}=44 \%$, $\mathrm{c}^{2}=54 \%, \mathrm{e}^{2}=2 \%$, o que sugere que o tempo despendido na prática desportiva é mais influenciável por factores do envolvimento comummente partilhados no seio da família do que pelos genes.

O único estudo português sobre esta temática foi realizado por Maia e col. (1999) numa amostra de 104 pares de gêmeos $(40 \mathrm{MZ}$, idade $=17,30 \pm 5.82 ; 64 \mathrm{DZ}$, idade $=17.86 \pm 8.12)$ do norte do país.

O cálculo dos valores de prática desportiva foi efectuado a partir do questionário de Baecke e col. (1982). Para além de uma resposta dicotômica (pratica/não pratica) o questionário permite estimar o valor de tal prática, com base no cálculo de um índice de prática desportiva que considera a intensidade (estimativa do dispêndio energético por modalidade), a duração da prática ( $\mathrm{n}$. $^{\circ}$ de horas semanais), bem como a freqüência ( $\mathrm{n}^{\circ}$ de meses por ano).

Na tabela 12 são apresentados os resultados relativos aos valores de concordância de prática desportiva bem como dos coeficientes de correlação tetracóricos.

\begin{tabular}{|c|c|c|c|c|c|}
\hline \multicolumn{6}{|c|}{ Concordância (\%) } \\
\hline Gémeos & Pares (n) & Ambos & Só 1 & Nenhum & $r_{s}$ \\
\hline$M_{\mathrm{n}}$ & 25 & 80.0 & 40 & 16.0 & 0.95 \\
\hline $\mathbf{M}$ & b & 35.0 & 50.0 & 150 & 0.41 \\
\hline $\mathrm{CZ}_{\mathrm{n}}$ & 15 & 14.7 & 20.6 & 647 & 0.42 \\
\hline $\mathrm{Dq}_{\mathrm{t}}$ & 29 & 333 & 29.6 & 37.1 & 0.47 \\
\hline $\mathrm{OZ}_{\mathrm{s}}$ & 15 & 267 & 40.0 & 333 & 0.44 \\
\hline
\end{tabular}

Tabela 12: Valores de concordância de prática desportiva nos gêmeos MZ e DZ dos dois sexos, bem como dos coeficientes de correlação tetracóricos $\left(r_{t}\right)$

Da análise dos valores foi possível tecer os seguintes comentários:
- os valores mais elevados de prática desportiva conjunta ocorre nos gêmeos $\mathrm{MZ}$ sendo a sua concordância muito superior à dos $\mathrm{DZ}_{\mathrm{m}}$. Em contraste, para o sexo feminino o valor de prática conjunta dos DZ é mais elevado do que MZ;

- o padrão de correlação mostra, sobretudo no sexo masculino, uma agregação familiar clara $\left(\mathrm{r}_{\mathrm{MZm}}>\mathrm{r}_{\mathrm{DZm}}\right)$-Esta diferença é uma indicação segura da presença de influências genéticas na diferente adesão à prática do desporto, nesta amostra;

- no sexo feminino, os valores de $r$ não seguem o padrão esperado para evidenciar a presença inequívoca de efeitos genéticos, uma vez que o valor de $\mathrm{r}_{\mathrm{MZf}}$ não é superior ao $\mathrm{r}_{\mathrm{DZf}}$;

- o valor de $\mathrm{r}_{\mathrm{DZso}}$ não é significativamente distinto dos valores de $\mathrm{r}_{\mathrm{DZm}}$ e $\mathrm{r}_{\mathrm{DZf}} \mathrm{o}$ que sugere a presença de factores do envolvimento que contribuem para a adesão da prática do desporto, em detrimento dos aspectos genéticos.

A metodologia de ajustamento de modelos revelou que o que melhor se ajustou aos dados e que mostrou melhorias substanciais relativamente aos outros é o modelo genético não implicando a presença de genes distintos a operar nos dois sexos.

Na tabela 13 encontram-se os resultados do modelo final (ACE) que se revelou mais parcimonioso e de melhor ajustamento aos dados.

\begin{tabular}{lccc}
\hline Sexo & $\mathrm{a}^{2}$ & $\mathrm{c}^{2}$ & $\mathrm{e}^{2}$ \\
\hline Masculino & 0.82 & 0.08 & 0.10 \\
Feminino & 0.00 & 0.71 & 0.29 \\
\hline
\end{tabular}

Tabela 13: Valores das estimativas de variância dos parâmetros fundamentais do modelo genético (ACE) em cada sexo.

No sexo masculino, os resultados evidenciam um forte efeito genético nos seus índices de prática desportiva, dado que $\mathrm{a}^{2}=0.82(82 \%$ da variância total é devida a diferenças genéticas entre os sujeitos). No sexo feminino a estimativa do efeito genético é zero sendo elevado o valor dos efeitos referentes ao envolvimento comumente par- 


\section{ㄱ.}

tilhado no seio da família $\left(\mathrm{c}^{2}=0.71\right)$.

\subsection{Estudos de Dispêndio Energético}

Tal como já foi referido no capítulo 2 deste trabalho, o dispêndio energético total é normalmente fraccionado em três componentes distintas: dispêndio energético basal (DEB); dispêndio energético associado aos processos de ingestão, digestão, transformação e armazenamento dos macro-nutrientes e dispêndio energético associado à actividade física quotidiana.

Cerca de $70 \%$ do dispêndio energético diário é gasto com a taxa de metabolismo basal. Esta taxa é apenas ligeiramente mais baixa que o dispêndio energético de repouso. A energia despendida nesta componente basal ou de repouso) está intimamente relacionada com a idade e o sexo, assim como com a quantidade de massa magra (massa isenta de gordura) do indivíduo. A massa magra explica, por si só, 50 a $80 \%$ da variação coservável na taxa de metabolismo de repouso (TMR). Estima-se que a variação intra-individual seja de 4 a $6 \%$ (Bouchard e col. 1997).

Depois de se ajustarem os valores da TMR para a composição corporal, idade e sexo do sujeito, a variação residual que subsiste é ainda cerca de 10\%. A esta porção de variância "inexplicável" têm sido atribuídos fac:ores genéticos. Para testar esta hipótese, foram realizados alguns estudos, embora muito poucos tenham gêmeos nas suas amostras.

Fontaineecol. (1985) realizaram uma pesquisa com o propósito de investigar a influência da hereditariedade no DEB em 20 pares de gêmeos MZ e 19 DZ. Foram encontrados valores de correlação intraclasse nos $\mathrm{MZ}$ que variaram entre 0.45 e 0.81 (de acordo com a unidade usada para expressar o DEB), valores esses que foram superiores aos dos DZ que se situaram entre 0.21 e 0.44. Resultados semelhantes foram encontrados por Bouchard e col. (1989). As correlações nos pares de gêmeos $\mathrm{MZ}(0.72$ a 0.79$)$ foram superiores as encontradas nos DZ ( 0.30 a 0.50$)$. A estimativa de heritabilidade encontrada neste estudo sugere que $70 \%$ da variância observada no DEB, depois do ajustamento para a idade, sexo, massa corporal e composição corporal, pode ser atribuída a factores genéticos. Os resultados destes estudos parecem sugerir, sem sombra de dúvida, que factores genéticos governam o dispêndio energético basal do indivíduo.

Apesar de existir uma variabilidade considerável entre os indivíduos, a magnitude do efeito relacionado com a segunda componente, que diz respeito ao efeito térmico da alimentação, representa cerca de $10 \%$ do dispêndio energético diário total. Do nosso conhecimento, apenas um estudo, cuja amostra continha gêmeos (21 pares de gêmeos DZ e $37 \mathrm{MZ}$ ), foi realizado com o propósito de analisar a influência dos factores genéticos nesta componente (Bouchard e col., 1989). O dispêndio energético foi registado, por calorimetria indirecta, durante 4 horas após a ingestão de uma refeição de $1.000 \mathrm{kcal}$. As correlações encontradas para os DZ e MZ foram de 0.35 e 0.52 respectivamente, sugerindo um efeito genético de $30 \%$ para o efeito térmico da alimentação.

Estudos que tenham investigado os factores genéticos responsáveis pelo dispêndio energético relacionado com a terceira componente - actividade física diária são também escassos. Tal facto deve-se, principalmente, a dificuldades metodológicas subjacentes à avaliação do dispêndio energético associado à actividade física em condições de "free-living". Ou seja, não é fácil avaliar, de forma isolada, a energia que o indivíduo gasta na actividade física quotidiana. Incontestavelmente, a actividade fisica exerce o efeito mais profundo e variável sobre o consumo de energia nos humanos (McArdle e col., 1992). Em condições de "free-living", aenorme dispersão nos valores de actividade física do sujeito representam a maior fonte de variação no dispêndio energético total diário entre indivíduos (Goran, 1997).

De acordo com Goran (1997), não havia, até à data, nenhum estudo publicado, em gêmeos ou em famílias com recurso à técnica do "Double labeled water" para a avaliação do dispêndio energético em condições de "free - living". Essa avaliação pode ser realizada combinando este método, para medir o dispêndio energético total, com a calorimetria indirecta, para medir o dispên- 
dio energético de repouso e o efeito térmico da alimentação. Este autor recorreu ao "Double labeled water" para avaliar o dispêndio energético total, durante 14 dias, de 37 pares de irmãos (com idades entre os 5 e os 9 anos), 5 dos quais eram gêmeos DZ. O dispêndio energético de repouso foi medido através da calorimetria indirecta. A correlação intra-par do dispêndio energético associado à actividade física foi de 0.11 . Uma vez que essa correlação foi calculada depois de efectuado o ajustamento do dispêndio energético total para o dispêndio energético de repouso, os valores sugerem a existência de influências genéticas diversas a governar a TMR e a taxa de dispêndio energético associada à actividade física.

Em síntese, os estudos referidos pretendem mostrar o seguinte conjunto de idéias:

-1) que a actividade física é governada por um conjunto indeterminado de genes; 2) que a actividade física não é um traço de natureza mendeliana, apesar de variações num só gene poderem alterar drasticamente um comportamento que é normalmente influenciado por vários genes (como se poderá observar no estudo da Drosophila melanogaster) e 3) que se começa a investigar a localização de bandas ou zonas em determinados cromossomas onde estarão alojados genes responsáveis pela variação no comportamento actividade física (estudos de QTL).

- que os valores de similitude dos pares de gêmeos MZ para o fenótipo actividade física são, quase sempre, superiores aos dos DZ; as características genéticas dos sujeitos parecem contribuir indubitavelmente para a variação observada no fenótipo actividade fisica, a que se adicionam as influências do envolvimento partilhado no seio da família e do envolvimento único dos sujeitos.

- que os resultados dos estudos evidenciam a presença de factores genéticos a governar a variação interindividual na prática desportiva, se bem que para o sexo feminino os factores do envolvimento pareçam ter um maior contributo nessa variação.

- que o dispêndio energético total é um fenótipo complexo que compreende as taxas de metabolismo basal e de repouso, o efeito térmico dos alimentos e o dispêndio energético na actividade física. Embora poucas pesquisas tenham abordado estas questões, os resultados conhecidos parecem sugerir que os factores genéticos contribuem para as diferenças interindividuais no dispêndio energético.

\section{Referências}

BEUNEN,G.;M.THOMS.GmericdetErrninantsofsports participation and daily physical activity. International Journal of Obesity, v. 3, p. 1-9,1999.

BLAIR, S.;S. BRODNEY. Effects of physical inactivity and obesity on morbidity and mortality: current evidence and research issues. Medicine \& Science in Sports \& \&ercise,v.31,n.11)p.S646-S662,1999.

BOOMSMA, D.I.; M.B.D.VANDERBREE-J. F. ORLEBEKE; P.C.M. MOLENAAR Resemblances ofparents and twins in sports participation and heart rate. Behavioral Genetics, v.19,n.1,p.23-14,1989.

BOUCHARD,C., and T.RANKINEN. Individualdirferences in response to regular physical activity. Medicine \& Science in Sports \& Exercise, v.33, n.6, p. S446-451, 2001.

BOUCHARD., C; A. TREMBIAY; A. NADEAU; J.P.DESPRÉS;

G.THÉRIAULT; M.R.BOULAY; C. LORTIE; C. LEBLANC, and G. FOURNIER Genetic efFect in resting and exercise metabolic rates. Metabolism v.38, n.4, p. 364-370,1989.

\section{BOUCHARD, $\mathrm{C} ; \mathrm{R}$.}

SHEPARDandT.STEPHENS.Physical activity, Fitness and health: International Proceedings and Consensus Statement. Champaign. HumanKinetics, Illinois, 1994. BOUCHARD,G;RJ.SHEPHARD;T.SIEVTJ «.Ger^of fitness and physical performance. Campaign, Human Kinetics, 1997.

CASPERSEN,G.J.; P.NIXON; R.DURANT. Physicalactivity Epidemiology applied to Children and adolescents. Exercise and Sport Sciences Review, v.26, p.341-403, 1998.

CDC: Physical Activity and Health: a report of the 
Surgeon General Adanta: U.S. Department of Health and Human Services, 1996.

DEFRIES,J.C.;M.C.GERVAIS, and

E.A.THOMAS.Response to 30 Generations of Selecdon for Open-Field Activity in Laboratory Mice. Behavior Genetics, v.8, n. 1, p. 3-13, 1978.

FALCONER, D.S. Introduction to quantitative genetics. Essex, Longman Scientific \& Technical, 1990.

FLINT, J.; R.

CORLEY;J.C.DeFRIES;D.W.FULKER;J.A GRAY;S.MILLER, and A.C. COLLINS.

Asimplegeneticbasis for a complex phychological trait in laboratory mice. Science, n.269, p. 1432-1435,1995.

FONTAINE,E;R.SAVARD;A.TREMBLAY;JP.DESPRE S;E POEHLMAN, C BOUCHARD.Resring metabolic rate in monozygotic and dizygotic twins. Acta Genet. Med. Gemellol. v.34, p.41 -47,1985.

GORAN, M.I.. Genetic influences on human energy expenditure and substrate utilization. Behavior Genetics, v27,n.4,p.389-399, 1997.

GRAÇA, L.M. Medicina materno-fetal: fundamentos e prática clínica. Volume II, Lisboa, 1996.

KAPRIO,J.;M.KOSKENVUO;S.SARNAGgarette smoking, use of alchool, and leisure-time physical activity among same-sexed adult male twins. In Progress in Clinicai and Biological Research. Allan R Liss, New York, p. $37-46,1981$.

KESANIEMI, Y.A.;E.DANFORTH;M.D.JENSEN;P.G. KOPELMAN; P. LEFEBVRE; B.A. REEDER. Dosereponse issues concerning physical activity and health: an evidence-based symposium. Medicine \& Science in Sports \& Exercise, v.33, n. 6, p. S351-358,2001.

KHOURY, M.J.; BEATY; B.H. GOHEN. Fundamentakof genetic epidemiology. New York, Oxford University Press, 1993

\section{KILLORON,A.;P.FENTEM;C.CASPERSON} (1994):Moving On. International perspectives on promoting physical activity. Health Educarion Authority.

KOOPMANS,JR;LJP.VANDOOMEN;D.I.BOOMSMA. Smoking and sports participation. In: GOLDBOURT, U.; U. de FAIRE; K. BERG, eds. Factors in coronary heart disease. Dordrecht, KluwerAcademic,p.217-235,1994.

LAUDERDALE, D.S. R. FABSITZ; J.M. MEYER; P. SHOUNSKY;V.RAMAKRISHNAN; J.GOLDBERG..Familiar determinants of moderate and intense physical activity: a twin study. Medicine \& Science in Sports \& Exercise, v29,n.8,p.1062-1068, 1997.

LIU, B.H. Statistical Genomics. CRC Press LLC, Bora Raton., 1998.

MAIA, JAR. Aspectos genéricos da actividade física. Um estudo univariado em gêmeos. José Antônio Ribeiro Maia Editor. Actas do Seminário Genética e Práticas Desportívo-Motoras, FCDEF-UP, Porto, 2001.

MAIA,JAR;V.LOPES;F.P.MORAIS.Actividade física e aptidão física associada à saúde. Um estudo de epidemiologia genética em gêmeos e seus progenitores do arquipélago dos açores. DREFD e FCDEF (eds). Porto, 2001.

MAIA, J.A.R.;R.LOOS;G. BEUNEN; M. THOMIS;R. VLIETING; F.P.MORAIS;V.P. LOPES.Aspectos genéticos da prática desportiva: um estudo em gêmeos. Revista Paulista de Educação Física, v. 13, n. 2, p. 160176, 1999.

MAYTO, A.R. and J.R. HOFSTETTER. AQTL for theGenetic Variance in Free-Running Period and Level of Locomotor Activity Between Inbred Strains of Mice. Behavior Genetics,v.29,n.3,p.171-176,1999.

MAYEDA, A.R.and

J.R.HOFSTETTER;J.K.BELKNAP;J.I.

NURNBERGER Hypothetical quantitative trait loci (QTL) for circadian period of locomotor activity in $\mathrm{CXB}$ recombinant inbred strains of mice. Behavior Genetics, v.26, n.5, p. 505-510,1996.

MCARDLE,W.D.;F. IKATCH, \& V.L. KATGH (1992): Fisiologia do Exercício: Energia, Nutrição e Desempenho Humano. Guanabara Koogan S A, Ro de Janeiro.

MONTOYE, H.; H.KEMPER; W.SARIS and RWASHBURN. Measuring Physical Activity and Energy Expenditure.

Human Kinetics, Champaign, Illinois, 1996.

PÉRUSSE, L;A. TREMBIAY;C. LEBLANC; C.BOUCHARD. Genetic and environmental influences on level of habitual physical activity and exercise participation. Am. J. 
Epidemiology, v.129,n.5,p. 1012-1022,1989.

PLOMN,R;J.CDEFRIES;G.E.M.CLEAN;M.RUTTER

Behavioral Genetics. $3^{\text {a }}$ edição, H. Freeman and Company, New York, 1997.

PLOMN,R.;J.C.DEFRIES;G.E.MCCLEAN;M.RUTT

ER Behavioral Genetics. $4^{\mathrm{a}}$ edição, H. Freeman and

Company.NewYork, 2000.

ROGERS,L;MCMAHONEY;L.ALMSY;A.G..COMUZZI

E; J. BLAUGERO. Quantitative Trait Linkage Mappingin Anthropology. Yearbook of PhysicalAnthropology, n.42,p.127-15,1999.

SALLIS, J.; N. OWEN. Physical Activity \& Behavioral Medicine. Sage publications, California, 1999.

SOKOLOWSKI,M.B;R.J.GREENSPAN;H.S.PEREIRA;A. COULTHARD;R.A.SHAW;E.BURGESS;A.ROBICHON and KA. OSBORNE. Natural behavior polimorphism due to a cGPM-dependent protein kinase of drosophila. Science, n.277,p.834,1997.

TURNER,J.R.;L.R.CARDON and J.K.HEWITT. Behaviour Genetic Approaches in Behavioural Medicine. Plenum Press, New York, 1995.

\section{Notas}

Credenciais:

* Maria Madalena Castro Oliveira (Mestre em Ciências do Desporto)

** José Antônio Ribeiro Maia, (Ph.D. Professor Associado da Faculdade de Ciências do Desporto e de Educação Física; responsável pelo Laboratório de Cineantropometria e Estatística Aplicada)

Local de actividades:

Laboratório de Cineantropometria e Estatística Aplicada Faculdade de Ciências do Desporto e de Educação Física Rua Dr. PlácidoCosta, 91 - 4200 Porto email: jmaia@fcdef.up.pt

Enviar correspondência para:

José Antônio Ribeiro Maia

Faculdade de Ciências do Desporto e de Educação Física Laboratório de Cineantropometria e Estatística Aplicada Rua Dr. PlácidoCosta, 91 - 4200 Porto email: jmaia@fcdef. up.pt
$1 \mathrm{cM}$ - centimorgam. Um cM é equivalente a 1 milhão de pares de bases

2As consultas foram efectuadas no Sportdiscus e Medline, no manual de Bouchard e col. (1997) e nos textos recentes de Beunen \&Thomis (1999) eMaia (2001).

Recebido em:02.10.01

Aceito em: 27.05.02 